\title{
A Numerical Study on Thermal Elastohydrodynamic Lubrication of Coated Polymers
}

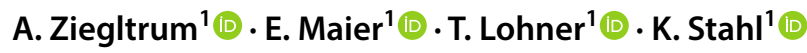

Received: 17 February 2020 / Accepted: 15 May 2020 / Published online: 1 June 2020

(c) The Author(s) 2020

\begin{abstract}
The application of polymers in power-transmitting machine elements, e.g., gears, is limited by moderate thermo-mechanical properties and the detrimental accumulation of contact heat, even with external lubrication. Hence, polymer rolling-sliding elements are often prone to thermo-mechanical overload or abrasive wear. Diamond-like carbon (DLC) coatings are well known from steel applications for enhancing wear resistance and reducing friction. Since preliminary results indicate promising results for such coatings for polymers as well, their influence on the behavior of lubricated polymer contacts is investigated by numerical simulation. For polymer-steel contacts, the mechanical and thermophysical properties of coating and polymer are varied. The contact geometry is dominated by a local conformity, in which most of the deformation is related to the polymer. The DLC coatings affect film thickness and hydrodynamic pressure only little even for untypical high coating thicknesses. In contrast, the contact temperature decreases already for very thin coatings due to enhanced heat removal. Hence, DLC coatings can act as a thermal barrier protecting the polymer from detrimental heat and protecting the polymer from abrasive wear.
\end{abstract}

Keywords Coatings $\cdot$ Polymers $\cdot$ Thermal elastohydrodynamic lubrication $\cdot$ Soft contact $\cdot$ Heat management

$\begin{array}{ll}\text { Abbreviations } \\ c_{\mathrm{p}} \quad \text { Specific heat capacity in } \mathrm{J} /(\mathrm{kg} \mathrm{K}) \\ e & \text { Thermal effusivity in } \mathrm{J} /\left(\mathrm{K} \sqrt{\mathrm{s}} \mathrm{m}^{2}\right) \\ E & \text { Young's modulus in } \mathrm{Pa} \\ E^{\prime} & \text { Reduced elastic modulus in } \mathrm{Pa} \\ F_{\mathrm{N}} & \text { Normal force in } \mathrm{N} \\ h & \text { Film thickness in } \mathrm{m} \\ h_{\mathrm{c}} & \text { Central film thickness in } \mathrm{m} \\ l_{\mathrm{eff}} & \text { Effective contact length in width direction in } \mathrm{m} \\ p & \text { Hydrodynamic pressure in Pa } \\ R_{x} & \text { Reduced radius of curvature in } \mathrm{m} \\ \mathrm{SRR} & \text { Slide-to-roll ratio in } \% \\ t & \text { Thickness in m } \\ T & \text { Temperature in } \mathrm{K} \\ v_{\mathrm{g}} & \text { Sliding velocity in } \mathrm{m} / \mathrm{s}\end{array}$

This paper is an extended version of an abstract presented in the $22^{\text {nd }}$ International Colloquium on Tribology 2020, Esslingen, Germany, 28-30 ${ }^{\text {th }}$ of January 2020.

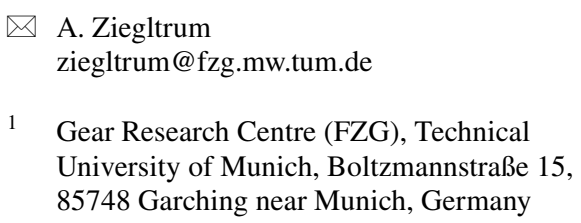

$$
\begin{array}{ll}
v_{\Sigma} & \text { Sum velocity in } \mathrm{m} / \mathrm{s} \\
x & \text { Film thickness length direction in } \mathrm{m} \\
z & \text { Film thickness height direction in } \mathrm{m} \\
w & \text { Line load in } \mathrm{N} / \mathrm{m}
\end{array}
$$

\section{Greek symbols}

$\alpha_{\mathrm{p}} \quad$ Pressure viscosity coefficient in $\mathrm{Pa}^{-1}$

$\varepsilon_{\mathrm{zz}} \quad$ Elastic strain in $\%$

$\dot{\gamma} \quad$ Shear rate in $\mathrm{s}^{-1}$

$\eta \quad$ Dynamic viscosity in $\mathrm{Pa} \cdot \mathrm{s}$

$\vartheta$ Temperature in ${ }^{\circ} \mathrm{C}$

$\vartheta_{\mathrm{M}} \quad$ Bulk temperature in ${ }^{\circ} \mathrm{C}$

$\vartheta_{\text {max }}$ Maximum temperature in ${ }^{\circ} \mathrm{C}$

$\lambda \quad$ Thermal conductivity in $\mathrm{W} /(\mathrm{m} \mathrm{K})$

$\mu \quad$ Coefficient of friction

V Poisson's ratio

$\rho \quad$ Density in $\mathrm{kg} / \mathrm{m}^{3}$

$\tau \quad$ Shear stress in $\mathrm{Pa}$

\section{Indices}

$1 \quad$ Lower solid body

2 Upper solid body

c $\quad$ Coating

f Fluid 


\section{Introduction}

Moderate thermo-mechanical properties and detrimental accumulation of contact heat inhibit the application of polymers to power-transmitting machine elements, e.g., gears. Lubrication can increase the load-carrying capacity and improve heat management. Nevertheless, polymer rolling-sliding elements are often prone to thermo-mechanical overload or abrasive wear. Diamondlike carbon (DLC) coatings are well known from steel applications for enhancing wear resistance and reducing friction. Recent progress in coating technology enables the application of such coatings to polymers [1] and has the potential to improve the performance of polymer rolling-sliding elements.

Thermo-elastohydrodynamically lubricated (TEHL) contacts can be categorized according to the ratio of elastic deformation and viscosity behavior [2]. Typical lubricated steel contacts are hard TEHL contacts because the rolling elements are deformed, and the lubricant acts in a piezoviscous manner at high hydrodynamic pressure. Soft TEHL contacts, on the other hand, behave in an almost incompressible and isoviscous manner because of low hydrodynamic pressure [3]. They exhibit large deformations which can be greater than the film thickness [4]. The lubricant behavior is reported to be Newtonian $[5,6]$ or slightly non-Newtonian [7]. Soft TEHL contacts occur, e.g., in synovial joints and seals $[3,4]$. Based on the classification according to Johnson [8], lubricated polymer contacts such as polymer rolling bearings and polymer gears operate in a transition regime between the elastic-isoviscous soft TEHL and the elastic-piezoviscous hard TEHL regime [9]. Polymer materials can exhibit viscoelastic behavior and hysteresis friction, possibly causing incomplete recovery from previous deformation and eventually overheating and damage $[10,11]$. In addition to frictional heat in the TEHL contact [12], this limits the application of polymers in power-transmitting machine elements. In mixed lubrication, the low surface hardness of polymers can result in abrasive wear when paired with steel [13-15].

DLC coatings on rolling elements are well known in hard TEHL contacts. They can improve wear resistance and reduce solid and fluid friction [16-21]. The mechanical properties of coatings can influence the hydrodynamic pressure and deformation, whereas the thermophysical properties influence the contact temperature, thus affecting the effective viscosity in the TEHL contact and influencing fluid friction. In contrast, the lubricant film thickness is barely affected since the conditions in the contact inlet are hardly influenced $[22,23]$. For low coating thickness, the effect of coatings mechanical properties is typically negligible [20]. Bobzin et al. [1] demonstrate the application of adherent and flexible DLC coatings on a thermoplastic polymer by means of physical vapor deposition (PVD). In the coating process, temperature sensitivity, deformation capability, and chemical reactivity with solvents during cleaning process were thoroughly considered $[1,24]$. The resulting coating's mechanical properties and thickness are lower compared to DLC coatings on steel [1]. Results on a pin-on-disk test rig show $40 \%$ lower wear volume for the DLC-coated contact [1]. Detailed investigations pursuing on the potential of DLC coatings on polymers in TEHL contacts have not been found in the literature.

In the present study, the TEHL contact of uncoated and coated lubricated polymer-steel pairings is analyzed in order to understand its behavior and to evaluate the influence of DLC coatings. Numerical simulations were performed under representative polymer gear operating conditions. After a parametric study on principal relations in uncoated polymer-steel contacts, the influence of DLC coatings is presented. Thereby, the thickness of the coating as well as the mechanical and thermophysical properties of the coating and the polymer is investigated.

\section{Study Setup and Parameters}

To investigate the polymer-steel contact and the effects of coatings, the object of investigation and operating conditions were chosen in accordance with investigations by Maier et al. [25]. Accordingly, Fig. 1 shows a schematic representation of the considered contact between polymer

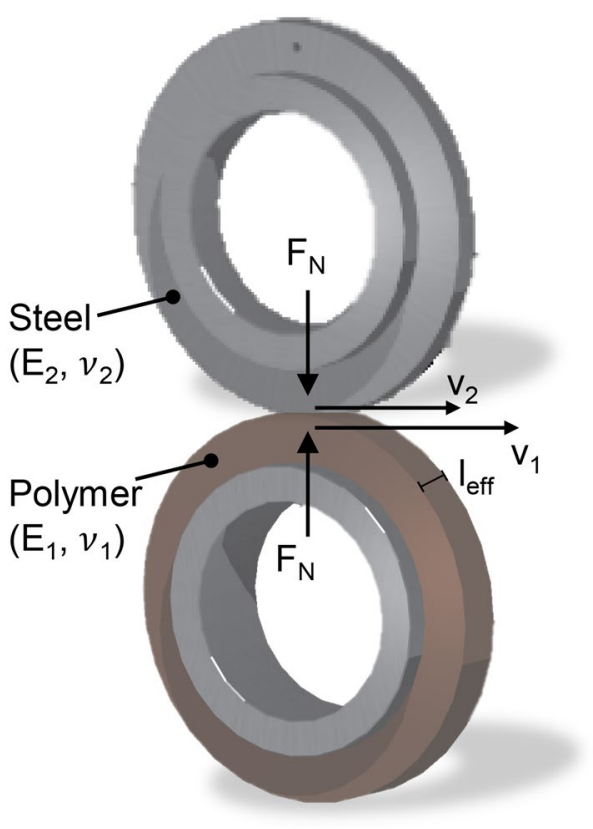

Fig. 1 Schematic representation of the main study setup 
and steel in the configuration of a twin-disk test rig. A line contact with a reduced radius of curvature of $R_{x}=20 \mathrm{~mm}$ was considered. The reference operating condition relates to a line load of $w=F_{\mathrm{N}} / l_{\text {eff }}=100 \mathrm{~N} / \mathrm{mm}$, a sum velocity of $v_{\Sigma}=8 \mathrm{~m} / \mathrm{s}$, a sliding velocity of $v_{\mathrm{g}}=3.43 \mathrm{~m} / \mathrm{s}$ (slide-to-roll ratio of SRR $=86 \%$ ) and a bulk temperature of $\vartheta_{M}=40^{\circ} \mathrm{C}$. The typical gear steel $16 \mathrm{MnCr} 5$ in a case-carburized state was considered. The polymer material properties considered were leaned on polymethyl methacrylate (PMMA). The polymer was considered in an uncoated and a DLC-coated configuration.

Table 1 shows the mechanical and thermophysical properties of the reference materials considered. Material properties of case hardened $16 \mathrm{MnCr} 5$ steel were adopted from [26]. Note that, recent publications [27-29] discuss the effect of thermal conductivity of steel in annealed and hardened state on EHL friction and temperature. It is pointed out that erroneously presumed values in EHL have led to an underestimation of temperature and overestimation of friction in high sliding conditions. The properties of the polymer were adopted from Marx et al. [3]. The a-C:H DLC coating considered was recently developed for polymers by Bobzin et al. [1]. Its thickness $t_{\mathrm{c}}$ and mechanical properties $E$ and $\nu$ were measured in [1]. The coating's thermophysical properties $\lambda, c_{\mathrm{p}}$ and $\rho$ were adopted from Becker et al. [30]. The thermal effusivity $e=\sqrt{\rho c_{p} \lambda}$, also known as thermal inertia in former studies [19,21], is supplemented, representing the ability to transport heat by conduction and convection [20].

Tri-(2-ethylhexyl)-trimellitate (TOTM) was used as reference lubricant, as specified by Bair [31]. At $40{ }^{\circ} \mathrm{C}$, it exhibits a dynamic viscosity of $\eta=85.7 \mathrm{mPa} \mathrm{s}$, a pressure viscosity coefficient of $\alpha_{\mathrm{p}}=19 \mathrm{GPa}^{-1}$ and a density of $\rho_{\mathrm{f}}=988 \mathrm{~kg} / \mathrm{m}^{3}$. A thermal conductivity of $\lambda_{\mathrm{f}}=0.14 \mathrm{~W} /(\mathrm{m} \mathrm{K})$ and specific heat capacity of $c_{\mathrm{p}, \mathrm{f}}=2000 \mathrm{~J} /(\mathrm{kg} \mathrm{K})$ were estimated. The Murnaghan equation of state [32] and the Doolittle equation of viscosity [33] were used to model density $\rho_{\mathrm{f}}(T, p)$ and low shear viscosity $\eta(T, p)$ depending on hydrodynamic pressure $p$ and temperature $T$. The non-Newtonian lubricant behavior $\eta\left(T, p, \dot{\gamma}_{f z x}\right)$ was modeled according to a modified CarreauYasuda equation $[34,35]$.

Table 1 Mechanical and thermophysical properties of the referenced materials considered

\begin{tabular}{llll}
\hline & Steel & Polymer & DLC \\
\hline$E$ in $\mathrm{GPa}$ & 210 & 2.9 & 34 \\
$\nu$ & 0.30 & 0.36 & 0.25 \\
$\lambda$ in $\mathrm{W} /(\mathrm{m} \mathrm{K})$ & 44 & 0.19 & 1.4 \\
$c_{\mathrm{p}}$ in $\mathrm{J} /(\mathrm{kg} \mathrm{K})$ & 431 & 1490 & 970 \\
$\rho$ in $\mathrm{kg} / \mathrm{m}^{3}$ & 7760 & 1180 & 2000 \\
$e$ in $\mathrm{J} /\left(\mathrm{K} \sqrt{\mathrm{s}} \mathrm{m}^{2}\right)$ & 12,130 & 578 & 1648 \\
$t_{\mathrm{c}}$ in $\mu \mathrm{m}$ & - & - & 1.0 \\
\hline
\end{tabular}

To study the behavior in uncoated polymer-steel TEHL contacts, a comparison to polymer-polymer and steel-steel contacts was initially conducted. Thereafter, by a variation of polymer's Young's moduli $E_{1}=\{0.8 ; 2.9 ; 7.0\} \mathrm{GPa}$, the effect of contact stiffness and by a variation of the thermal effusivity $e_{1}=\{435 ; 578 ; 2569\} \mathrm{J} /\left(\mathrm{K} \sqrt{\mathrm{s}} \mathrm{m}^{2}\right)$, the effect of thermophysical properties on the TEHL contact was investigated. A wide range of operating conditions were considered with sum velocities of $v_{\Sigma}=\{4 ; 8 ; 12\} \mathrm{m} / \mathrm{s}$ and line loads of $w=\{50 ; 100 ; 150\} \mathrm{N} / \mathrm{mm}$. The effect of coated polymers was studied by a variation of coating thickness $t_{\mathrm{c}}$ from $1 \mu \mathrm{m}$ to a hypothetical $500 \mu \mathrm{m}$ for different coating's Young's moduli $E_{\mathrm{c}}=\{34 ; 110 ; 220 ; 420\} \mathrm{GPa}$ and thermal effusivities $e_{\mathrm{c}}=\{578 ; 1156 ; 2312\} \mathrm{J} /\left(\mathrm{K} \sqrt{\mathrm{s}} \mathrm{m}^{2}\right)$. Hence, a wide range of mechanical and thermophysical properties of substrate and coating materials were considered in order to address typical polymers and coatings.

\section{TEHL Simulation Model}

The study on uncoated and coated polymer-steel TEHL contacts was conducted using a TEHL simulation model called TriboMesh. Its basics and structure are described in detail in $[19,25,36-38]$. Therefore, only the main physical and numerical characteristics are repeated below. The explanations and formulations employed are mainly based on [19, 36].

The TEHL simulation incorporated hydrodynamics, contact mechanics and energy conservation. The generalized Reynolds' equation according to Yang and Wen [39] was coupled with the linear elasticity equations, following the full-system approach based on a finite element formulation [40]. This system of equation is solved strongly coupled with the energy equations [41]. Thereby, a dimensionless formulation of equations and representation of calculation domains is applied. A free triangular mesh for the solid domains with a refinement at the lubricant-solid interface is used. The lubricant domain is represented by rectangular mesh with about 10 elements in gap height direction. The contact configuration in Fig. 1 is represented by a finite line contact simulation. The total deformation is calculated separately on two bodies with corresponding Young's modulus and Poisson's ratio. Coatings were considered in linear elasticity equations and energy equations by additional dimensionless computational domains [20]. Polymer is assumed to be linear elastic due to small strain (cf. Sect. 4.1.2). The effect of local contact temperature on polymer's Young's modulus was assumed to be negligible on TEHL contact stiffness due to the very low temperature penetration depth. Viscoelasticity was not considered [25, 42]. Stationary bulk temperatures are assumed. 
Shear stress $\tau_{f z x}$ accumulates of sliding friction from Couette flow and compression-induced friction from Poiseuille flow. In polymer-steel contacts, both can have same magnitude $[6,25]$. Hence, shear stress reads based on the generalized Reynolds' equation according to Yang and Wen [39]:

$\tau_{f z x}=\eta\left(p, T, \dot{\gamma}_{f z x}\right) \cdot \dot{\gamma}_{f z x}=\frac{\partial p}{\partial x}\left(z-\frac{\int_{0}^{h} \frac{z}{\eta} \mathrm{d} z}{\int_{0}^{h} \frac{1}{\eta} \mathrm{d} z}\right)+\frac{v_{2}-v_{1}}{\int_{0}^{h} \frac{1}{\eta} \mathrm{d} z}$

According to Eq. (1), the evaluation of the coefficient of friction $\mu$ in the middle of the lubricant film $z=h / 2$ neglects the shear stress induced by Poiseuille flow. Therefore, $\mu$ was evaluated on the polymer surface $(z=0)$.

$\mu=\frac{\left.\int_{\Omega} \tau_{f z x}\right|_{z=0} \mathrm{~d} x}{w}$

\section{Results and Discussion}

In this section, TEHL simulation results of uncoated and DLC-coated polymer-steel contacts are presented followed by a discussion of the main findings.

\subsection{Uncoated Polymer-Steel Contact}

Principle relations in uncoated polymer-steel contacts are described by a classification of polymer-steel contacts and variation of polymer's Young's modulus, thermal effusivity and operating conditions.

\subsubsection{Reference Operating Condition and Material Properties}

To classify polymer-steel TEHL contacts, the hydrodynamic pressure $\mathrm{p}$ and the film thickness $\mathrm{h}$ are compared in Fig. 2 for a polymer-steel, polymer-polymer and steel-steel material paring at the same line load. The reference material properties of Table 1 were considered.

Hydrodynamic pressure $\mathrm{p}$ and film thickness $\mathrm{h}$ of the material pairings considered show well-known distributions with almost no second pressure maximum and a constriction with a minimum film thickness. The comparable small hydrodynamic pressure $\mathrm{p}$ in the TEHL contacts is responsible for the absence of a second pressure maximum typically known from hard TEHL contacts. In correlation with stiffness of contact pairing, the deformations and contact areas are largest for the polymer-polymer and smallest for the steel-steel contact and, therefore, hydrodynamic pressure is highest for the steel-steel and lowest for polymer-polymer

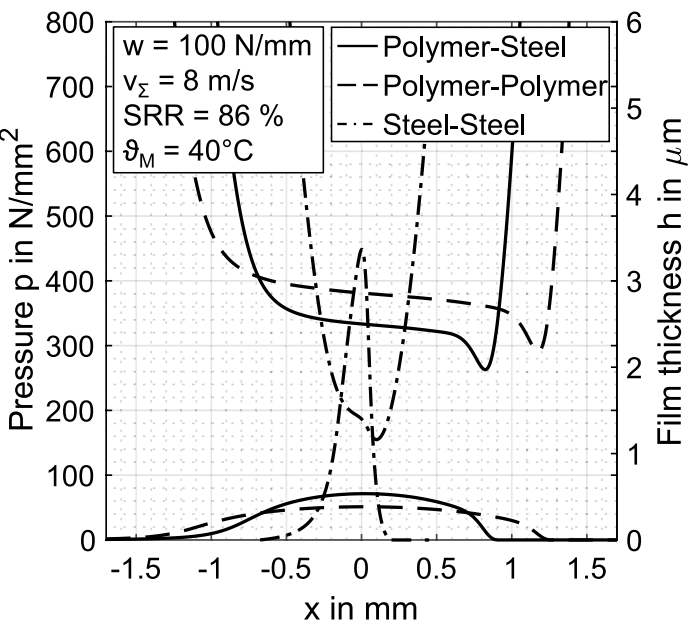

Fig. 2 Hydrodynamic pressure $p$ and film thickness $h$ of a polymersteel, polymer-polymer and steel-steel TEHL contact for the same line load

contact. As a consequence of the deformation, the film thickness for the polymer-polymer contact is higher than for the steel-steel contact. The characteristics of pressure and film thickness for the polymer-steel contact lay in between.

To analyze the division of deformation amongst the material pairing, Fig. 3 shows the undeformed and deformed geometry of the rolling elements in the polymer-steel (left), polymer-polymer (middle), and steel-steel contact (right). Note that individual deformations are considered separately in the numerical model. For the illustration, the approach towards the rolling elements according to the load balance is equally applied on the rolling elements.

The polymer-steel contact shows a local surface conformity: the polymer accounts for $98 \%$ of total deformation, and steel is nearly undeformed. The central contact zone shows a well-known parallel gap, but it is curved along the steel surface. In contrast, the polymer-polymer and steel-steel contacts show an equal division of deformation of the rolling elements.

In addition, Fig. 4 shows the temperature $\vartheta$ for the polymer-steel, polymer-polymer and steel-steel contacts. Note, henceforth the results are referenced in the equivalent system and on the lower surface. Note that, the figure's axes of steel-steel contact are adjusted for illustration purposes.

The temperature $\vartheta$ is highest for the steel-steel contact with a maximum contact temperature of $\vartheta_{\max }=90{ }^{\circ} \mathrm{C}$. In comparison, $\vartheta_{\text {max }}$ is $55^{\circ} \mathrm{C}$ for the polymer-polymer and only $48{ }^{\circ} \mathrm{C}$ for the polymer-steel contact. This can be explained by the heat sources in the TEHL contact due to shearing and compression of lubricant and heat removal due to convection and conduction. Higher hydrodynamic pressure $p$ results in higher viscosity, higher shear stress and, consequently, more pronounced heat generation. In contrast, heat removal 

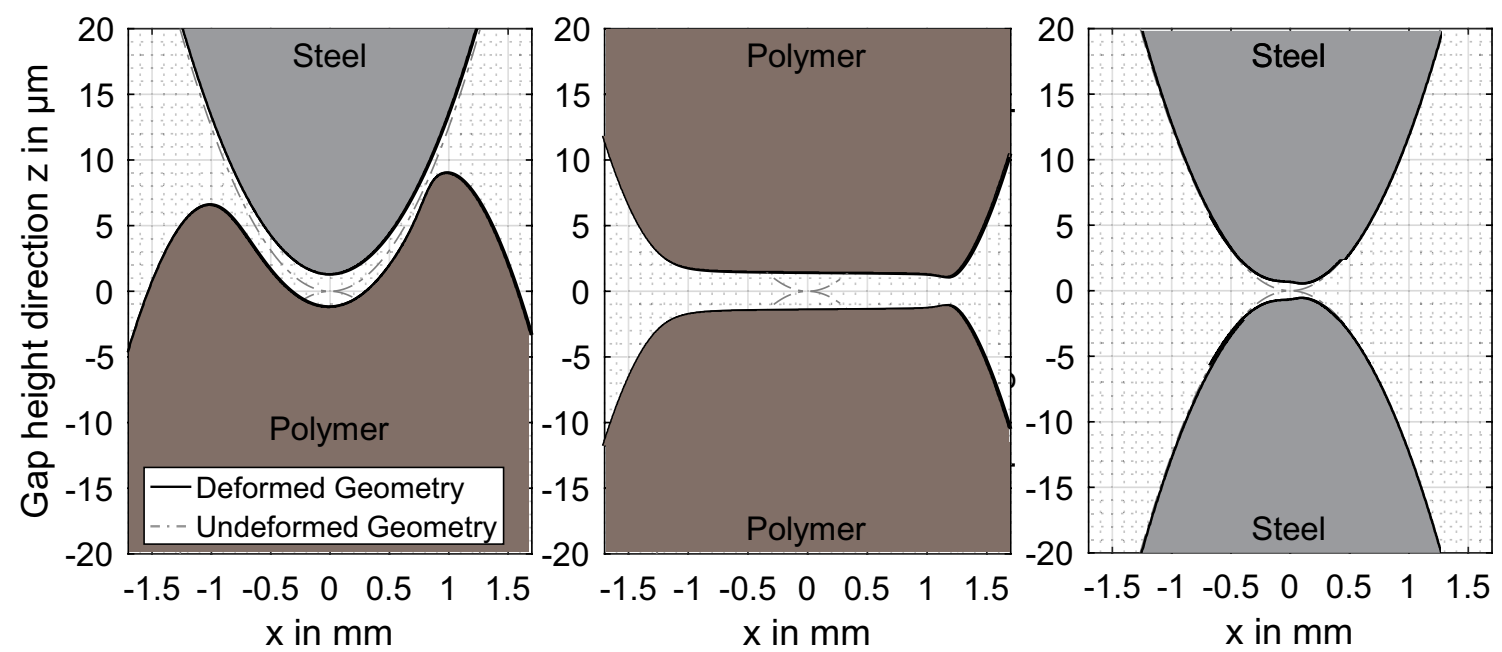

Fig. 3 Undeformed and deformed geometry of the rolling elements of a polymer-steel (left), polymer-polymer (middle) and steel-steel (right) TEHL contact for the same line load

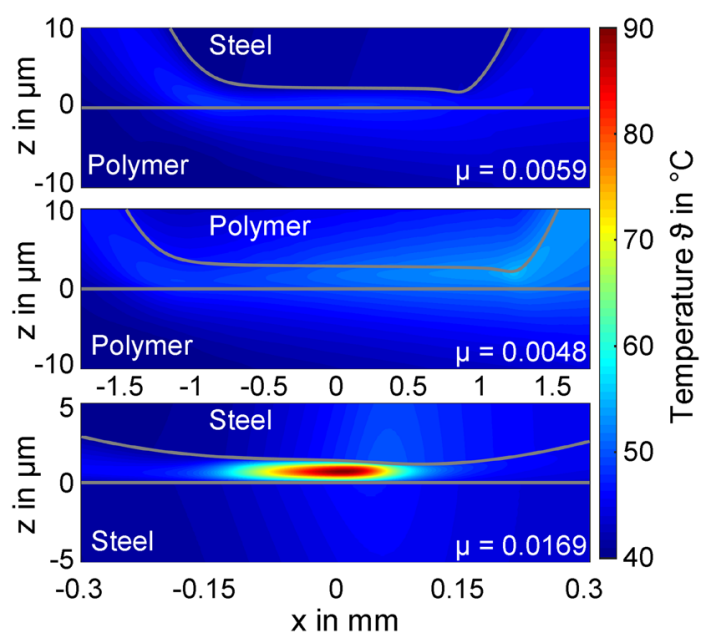

Fig. 4 Temperature $\vartheta$ of a polymer-steel, polymer-polymer and steel-steel TEHL contact for the same line load

from the TEHL contact is mainly determined by convection and conduction of the rolling elements. A lower thermal effusivity $e$ typically results in higher contact temperatures. For the steel-steel contact, $p$ and $e$ are highest, resulting in the most pronounced heat generation and removal. As a consequence, the temperature $\vartheta$ is concentrated in the middle of the lubricant film and the rolling elements are only sparsely heated. For the polymer-polymer contact, $p$ and $e$ are lowest, so heat generation and removal are weak. Thus, the temperature $\vartheta$ is much lower than the steel-steel contact. For the polymer-steel contact, $\mathrm{p}$ and therefore heat generation are slightly higher than the polymer-polymer contact. Since the steel shows a high value and the polymer shows a low value of e, thermal insulation is present on the polymer surface. Hence, in spite of the slightly higher heat generation compared to the polymer-polymer contact, the superior heat removal by steel results in the lowest contact temperature $\vartheta$.

The evaluation of the viscosity in the TEHL contacts for the polymer-polymer and polymer-steel contact follows the findings of Maier et al. [25] and shows almost no effect of shear thinning. Hence, the viscosity $\eta$ and therefore shear stress and coefficient of friction $\mu$ depend only on $p$ and $\vartheta$. For the steel-steel contact, shear thinning plays a role with $\eta\left(T, p, \dot{\gamma}_{f z x}\right)$ in maximum $25 \%$ lower than $\eta(T, p)$.

\subsubsection{Variation of Polymer Mechanical Properties}

Polymers available for gear application and their thermoelasticity feature a wide range of Young's moduli E. Figure 5 compares hydrodynamic pressure $p$, film thickness $h$ and temperature $\vartheta$ for a polymer's Young's moduli of $E_{1}=\{0.8$; $2.9 ; 7.0\} \mathrm{GPa} . E_{1}=2.9 \mathrm{GPa}$ corresponds to the reference value. A study on the effect of polymer's Poisson's ratio varied from $\nu=0.25$ to 0.50 only had a small effect on the TEHL contact, so it is therefore not explicitly shown here.

In general, the hydrodynamic pressure $p$ increases and film thickness $\mathrm{h}$ and contact width decrease with increasing Young's modulus of the polymer. For $E_{1}=7.0 \mathrm{GPa}$, the maximum pressure $p$ increases by $50 \%$ and the central film thickness $h_{\mathrm{c}}$ decreases by $20 \%$ compared to $E_{1}=2.9 \mathrm{GPa}$. For $E_{1}=0.8 \mathrm{GPa}$, a reduction of $p$ by $48 \%$ and an increase of $h_{\mathrm{c}}$ by $52 \%$ is observed. This can be traced back to the increasing stiffness and decreasing deformation of the polymer with increasing Young's modulus of the polymer.

With increasing $E_{1}$, the hydrodynamic pressure $p$ increases, which results in an increase of shear stress and 

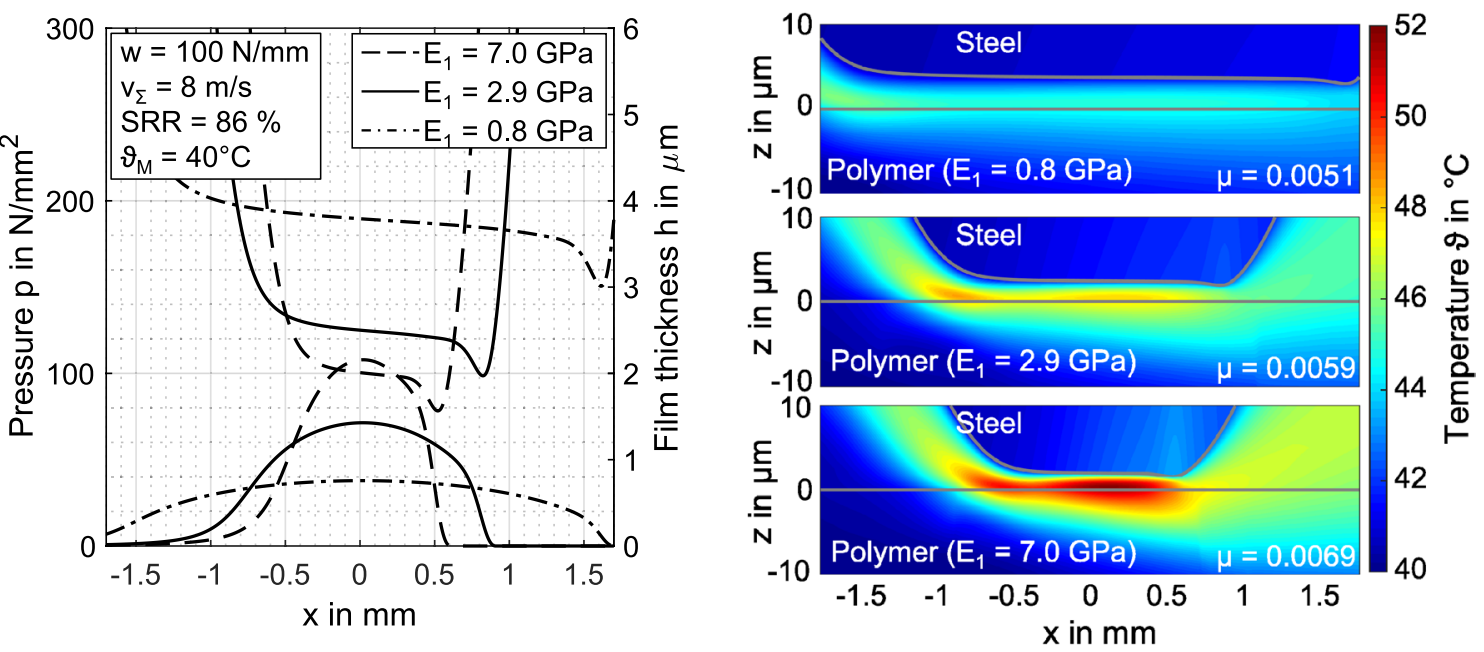

Fig. 5 Hydrodynamic pressure $p$ and film thickness $h$ (left) and temperature $\vartheta$ (right) of a polymer-steel contact with different polymer's Young's moduli $E_{1}$

coefficient of friction $\mu$. Hence, the temperature $\vartheta$ increases and $\mu$ decreases. Overall, the increase of shear stress and $\mu$ due to increasing pressure is larger than their decrease due to increasing temperature. For $E_{1}=7.0 \mathrm{GPa}, \mu$ increases by $17 \%$ and $\vartheta_{\max }$ by $7 \%$. For $E_{1}=0.8 \mathrm{GPa}, \mu$ decreases by $14 \%$ and $\vartheta_{\max }$ by $5 \%$. The temperature distribution shows for $E_{1}=0.8 \mathrm{GPa}$ and $E_{1}=2.9 \mathrm{GPa}$ higher values in the contact inlet than in the contact zone. This can be traced back to same magnitude of lubricant heat sources due to shearing and compression of lubricant. Hence, the temperature distributions confirm the same magnitude of heat and friction induced by Couette and Poiseuille flow in the TEHL contacts. These relations change with increasing $E_{1}$ (cf. $E_{1}=7.0 \mathrm{GPa}$ ) such that shear heating becomes dominant as known from hard TEHL contacts.

The evaluation of the viscosity shows almost no shearthinning effect for all considered $\mathrm{E}_{1}$ (cf. Sect. 4.1.1). This relation is expected to change with further increasing $E_{1}$.

Figure 6 shows the elastic strain $\varepsilon_{\mathrm{zz}}$ on the surface of the polymer rolling element for various polymer's Young's moduli $E_{1}$. Note that nearly the entire deformation in the contact is present in the polymer, whereas the steel is almost undeformed (cf. Fig. 3).

The elastic strain $\varepsilon_{\mathrm{zz}}$ on the surface of the polymer resembles the distribution of the hydrodynamic pressure $p$. Hence, $\varepsilon_{\mathrm{zz}}$ shows highest absolute values and widths for the lowest $E_{1}$ and the lowest absolute values and widths for the highest $E_{1}$. For $E_{1}=0.8 \mathrm{GPa}$, the absolute maximum strain is $95 \%$ higher than for $E_{1}=2.9 \mathrm{GPa}$. For $E_{1}=7.0 \mathrm{GPa}, \varepsilon_{\mathrm{zz}}$ is $36 \%$ lower. For the lowest $E_{1}=0.8 \mathrm{GPa}$, the maximum absolute elastic strain is $\varepsilon_{\mathrm{zz}}=2.9 \%$ in a material depth of $z \approx-0.6 b_{\mathrm{H}}$ and is a result of pressure. In exemplary stress-strain curves of a tensile test of, e.g., a PMMA material [43], linear elastic behavior is present

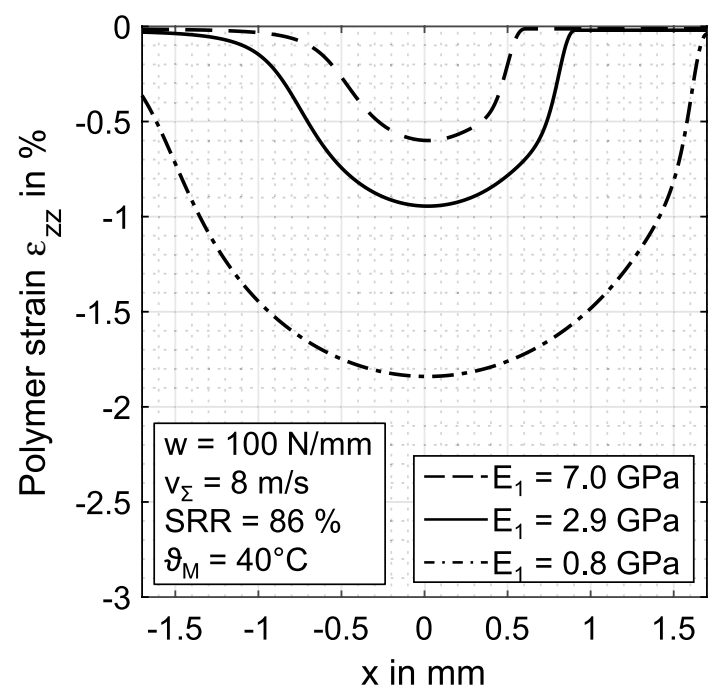

Fig. 6 Elastic strain $\varepsilon_{\mathrm{zz}}$ on the surface of the polymer for different polymer's Young's moduli $E_{1}$

until $\varepsilon_{\text {zz }} \sim<2 \%$. Yield strain is reached at $\varepsilon_{\text {zz }} \sim>4.5 \%$ [43]. Note that, whereas in tensile tests, material underlies tension, in TEHL contact the material underlies compression. Nonetheless, this indicates a good approximation of linear elastic material behavior in TEHL contacts.

Contact temperatures (Fig. 5) show small increases and penetration depths of lower than $10 \mu \mathrm{m}$, therefore the Young's modulus is weakly influenced and only in the surface near area of the polymer. Since the material areas which underlie strain and stress are much larger than the temperature penetration depth, no significant effect on pressure and film thickness is present. But high surface temperatures and the consequently lower mechanical stiffness can cause thermoplastic deformation and melting [25]. 


\subsubsection{Variation of Polymer Thermophysical Properties}

Similar to the Young's modulus, polymers for gear application feature a wide range of densities $\rho$, thermal conductivities $\lambda$, and specific heat capacities $c_{\mathrm{p}}$. These properties can be summarized by the thermal effusivity $e$ describing the ability of a material to transport heat. To evaluate the effect of different polymer thermal effusivity $\mathrm{e}_{1}$ on the steel-polymer TEHL contact, density $\rho=[1000 \ldots 1500] \mathrm{kg} / \mathrm{m}^{3}$, thermal conductivity $\lambda=[0.19 \ldots 2] \mathrm{W} /(\mathrm{m} \mathrm{K})$ and specific heat capacity $c_{\mathrm{p}}=[1000 \ldots 2200] \mathrm{J} /(\mathrm{kg} \mathrm{K})$ are varied. This results in considered thermal effusivities $e_{1}=\sqrt{\rho c_{p} \lambda}$ from 435 to $\left.2569 \mathrm{~J} /(\mathrm{K} \sqrt{\mathrm{s} \mathrm{m}})^{2}\right)$. The thermal effusivity of $\mathrm{e}_{1}=578 \mathrm{~J} /$ $\left(\mathrm{K} \sqrt{\mathrm{s} \mathrm{m}} \mathrm{m}^{2}\right)$ corresponds to the reference value. The Young's modulus and Poisson's ratio are kept constant as in Table 1. Figure 7 shows the hydrodynamic pressure $p$, film thickness $h$ and temperature $\vartheta$ for different polymer's thermal effusivities $e_{1}$.

The variation of the thermal effusivity of the polymer $e_{1}$ has a negligible influence on the hydrodynamic pressure $p$. The contact temperature $\vartheta$ decreases with increasing $e_{1}$. A high thermal effusivity $e_{1}$ results in a more pronounced heat removal. Hence, the temperature increase in the TEHL contact is smaller. For low $e_{1}$, the rolling element acts thermally insulating, so $\vartheta$ in the TEHL contact is higher. Additionally, $\vartheta$ is localized towards the polymer surface since heat accumulates there. As a consequence of higher temperatures in the TEHL contact, the coefficient of friction slightly decreases. Due to the more pronounced temperature in the contact inlet, the film thickness $\mathrm{h}$ decreases slightly by up to $0.2 \mu \mathrm{m}$ with decreasing $\mathrm{e}_{1}$.

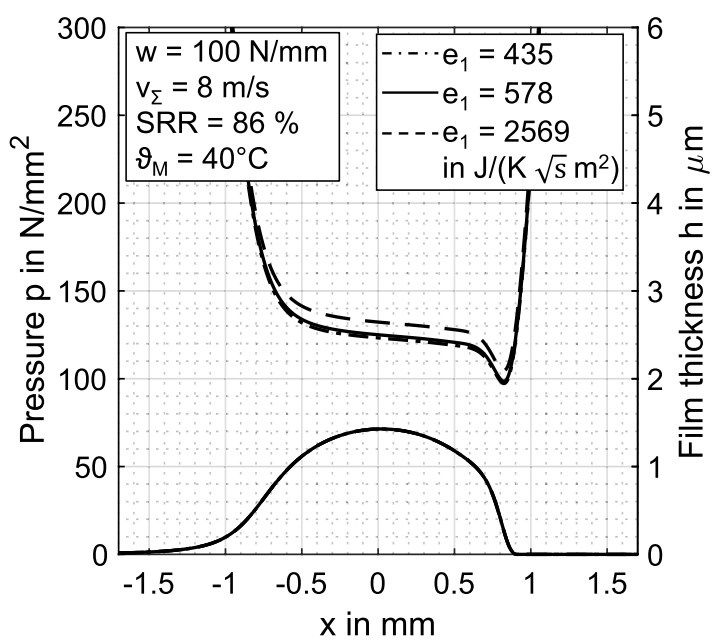

To analyze the influence of polymer's thermal effusivity $e_{1}$ on the TEHL temperature in more detail, Fig. 8 shows the surface temperature $\vartheta_{1}$ of the polymer.

The general trend of the polymer surface temperature $\vartheta_{1}$ shows an increase at the contact inlet to a maximum. This is due to compressive heat generation in the contact inlet, which is in the same order as lubricant shearing (cf. Sect. 4.1.2). After this maximum, the surface temperature decreases as the gradient of the hydrodynamic pressure and, therefore, heat generation due to compression of lubricant decreases. In the contact zone, heat generation due to shearing of the lubricant becomes dominant, resulting in

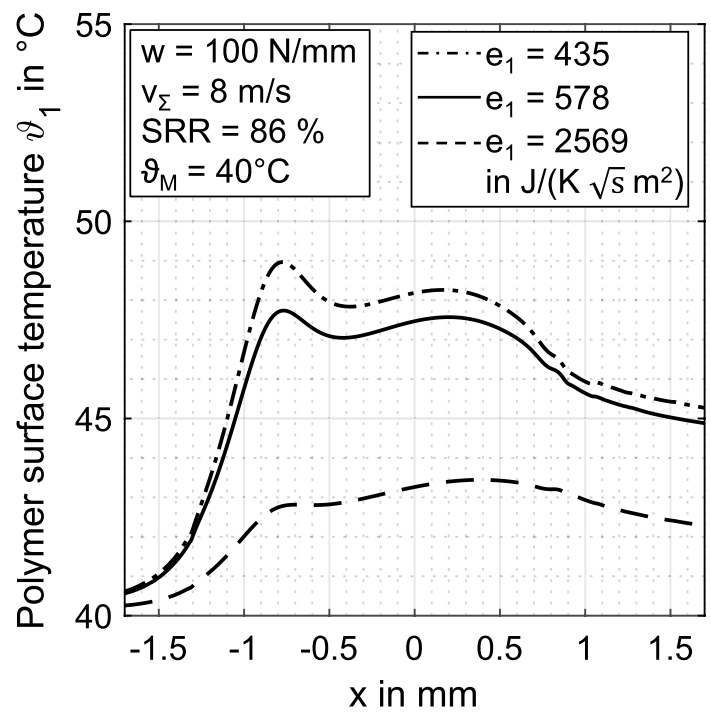

Fig. 8 Polymer surface temperature $\vartheta_{1}$ for different polymer's thermal effusivities $e_{1}$

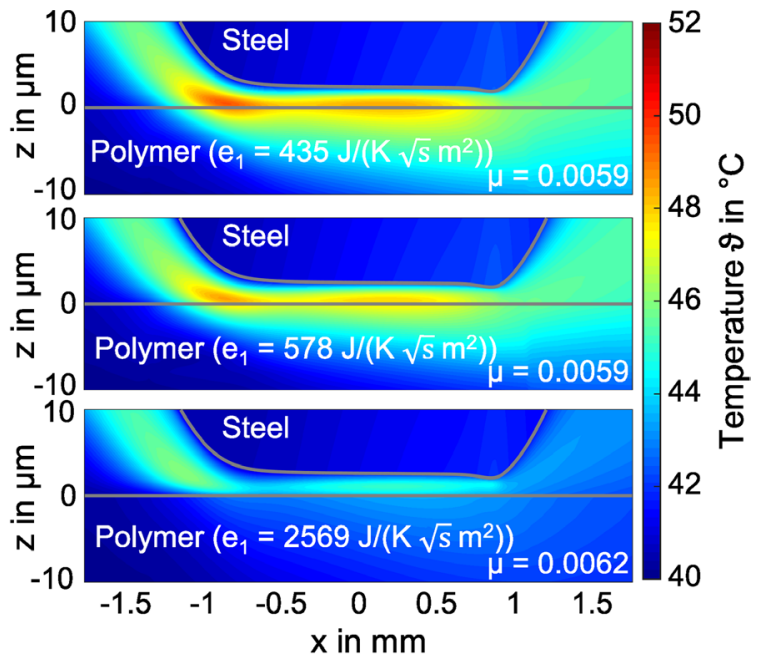

Fig. 7 Hydrodynamic pressure $p$, film thickness $h$ (left) and temperature $\vartheta$ (right) of a polymer-steel contact with different polymer's thermal effusivities $e_{1}$ 
a second maximum of $\vartheta$. Towards the contact outlet, the pressure gradient is negative, so lubricant expansion leads to heat removal. In the contact outlet, the heated polymer surface slowly transfers part of the heat into the lubricant. For low $e_{1}$, a high temperature increase with a pronounced temperature maximum in the contact inlet is observed, and vice versa for high $e_{1}$. The accumulation of heat in the contact inlet and the temperature level in the contact zone is reduced for high $e_{1}$ since heat removal by the polymer is more pronounced.

\subsubsection{Variation of Operating Condition}

Figure 9 shows the hydrodynamic pressure $p$, film thickness $h$ (left) and temperature $\vartheta$ in the middle of the lubricant film $z=h / 2$ (right) of the polymer-steel contact for different operating conditions by changing the sum velocity to $v_{\Sigma}=\{4 ; 12\} \mathrm{m} / \mathrm{s}$ and the line load to $w=\{50 ; 150\} \mathrm{N} / \mathrm{mm}$. $v_{\Sigma}=8 \mathrm{~m} / \mathrm{s}$ and $w=100 \mathrm{~N} / \mathrm{mm}$ correspond to the reference operating condition. The mechanical and thermophysical properties are kept constant as per Table 1.

The hydrodynamic pressure $p$ and contact width increase with increasing line load $w$, whereas the film thickness decreases. The central film thickness $h_{\mathrm{c}}$ is $8 \%$ lower at $w=150 \mathrm{~N} / \mathrm{mm}$ and $22 \%$ higher at $w=50 \mathrm{~N} / \mathrm{mm}$ compared to $w=100 \mathrm{~N} / \mathrm{mm}$. This is in accordance with the analytical formula according to Myers [9]. In contrast to hard TEHL, the formula according to Dowson and Higginson [44] shows for the load variation considered a change in $\mathrm{h}_{\mathrm{c}}$ of $-7 \%$ and $+12 \%$, respectively. With increasing sum velocity $\mathrm{v}_{\Sigma}$, $p$ is almost unaffected and $\mathrm{h}$ increases. This is well known from hard TEHL contacts.

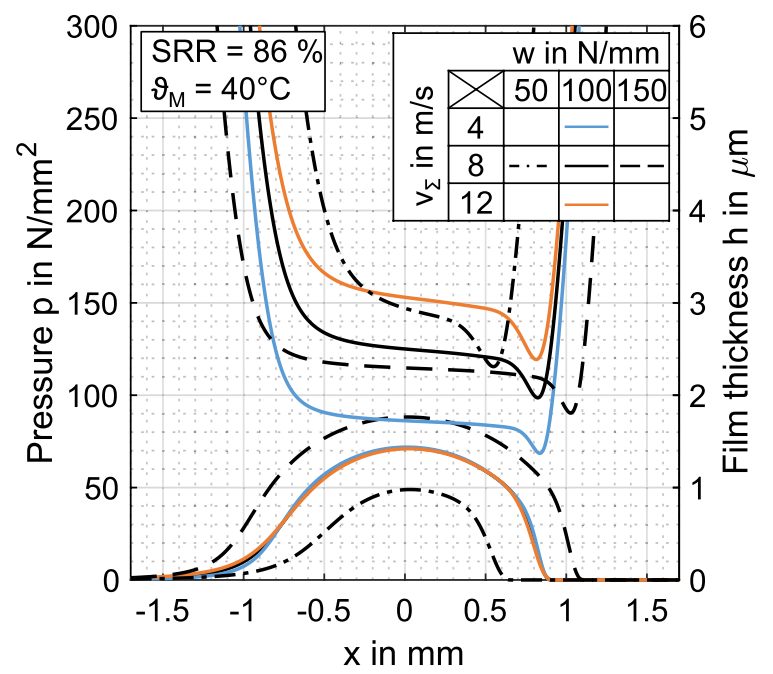

The temperature profiles $\vartheta$ in the middle of the lubricant film generally corresponds with the temperature of the polymer surface in Fig. 8. In contrast, the temperature $\vartheta$ in the contact inlet at $z=h / 2$ shows a higher level and a less pronounced increase than at the polymer surface. This can be traced back to lubricant backflow, which transports preheated lubricant from the contact region to the contact inlet. In the contact outlet, temperature $\vartheta$ decreases to a similar temperature $\vartheta$ as in the contact inlet. This confirms the same magnitude of heat sources by lubricant's compression and shearing.

When varying the operating conditions, a dominant influence of the sum velocity $v_{\Sigma}$ over the line load $w$ on the temperature $\vartheta$ is observed. With increasing line load $w$, the maximum of $\vartheta$ is almost unaffected. However, the trend of $\vartheta$ shows varying contact widths and temperature gradients. With increasing $v_{\Sigma}$, sliding velocity $v_{\mathrm{g}}$ increases with the same ratio as SRR is constant. This results in an increase in shear rate, because the increase of $h$ with increasing $v_{\Sigma}$ is less pronounced. Hence, shear stress (Eq. 1), and shear heating and therefore temperature $\vartheta$ rises. In the contact inlet, high compressive heating contributes to an increase of $\vartheta$, which affects the film thickness $h$. In the contact zone, $\vartheta$ increases more strongly since shear heating is more pronounced due higher sliding velocity $v_{\mathrm{g}}$ with increasing $v_{\Sigma}$.

\subsubsection{Interim Summary}

Based on the presented results, the main findings on uncoated polymer-steel TEHL contacts are summarized:

- Polymer-steel pairings result in a local contact conformity with a negligible deformation of steel.

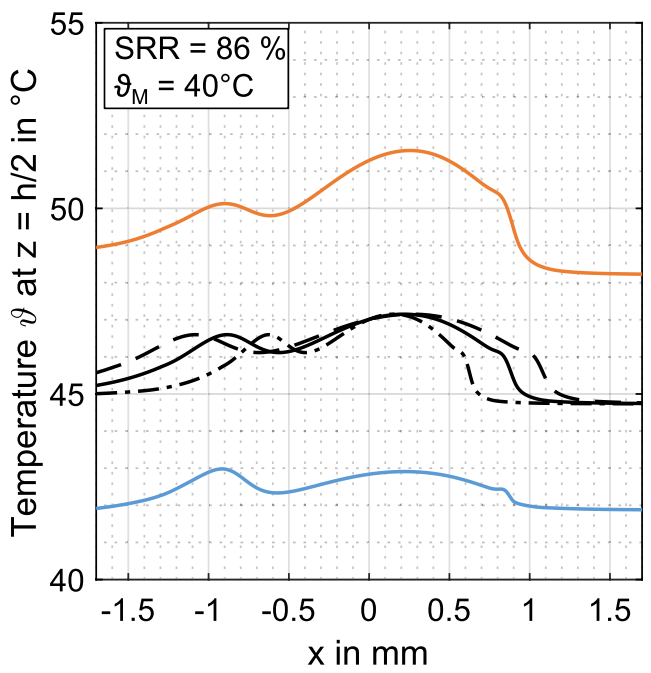

Fig. 9 Hydrodynamic pressure $p$, film thickness $h$ (left) and temperature $\vartheta$ at $z=h / 2$ (right) of polymer-steel contacts for different operating conditions with respect to $v_{\Sigma}$ and $w$ 
- Low thermal effusivity of polymers results in an insulation effect and localized temperature rises on the surface.

- Heat sources due to compression and shearing have a similar magnitude, such that pronounced heat generation in the contact inlet can be recognized.

- Linear elastic material behavior of polymers is a good approximation for contact analysis as elastic strains are small. Moreover, neglected temperature dependence of polymer's Young's modulus is also a good approximation as contact temperatures and heat penetration depths are small.

- With increasing Young's modulus of polymers, the characteristics of hard TEHL contacts emerge more clearly.

\subsection{Coated Polymer-Steel Contacts}

In this section, the influence of DLC coatings, its coating thickness and mechanical and thermophysical properties are investigated based on the reference in Table 1. Material properties of DLC were varied beyond the technical meaningful limits for polymers to study their sensitivity.

Figure 10 shows, by way of example, the hydrodynamic pressure $\mathrm{p}$, film thickness $h$ and temperature $\vartheta$ of a uncoated and coated polymer-steel contact for the coating thicknesses $t_{\mathrm{c}}=\{1 ; 20 ; 100\} \mu \mathrm{m}$. Whereas $t_{\mathrm{c}}=1 \mu \mathrm{m}$ corresponds to the thickness of the developed DLC coating for polymers in [1], the assumed thicknesses $t_{\mathrm{c}}=\{20 ; 100\} \mu \mathrm{m}$ are chosen for classification. Note that, only the polymer is DLC coated, whereas steel remains uncoated. The material properties correspond to the reference values in Table 1.

The coated contacts with $t_{\mathrm{c}}=\{1 ; 20\} \mu \mathrm{m}$ show very similar trends of $h$ and $p$ as the uncoated contact. For $t_{\mathrm{c}}=100 \mu \mathrm{m}$, $\mathrm{p}$ is slightly higher and shows a more pronounced second pressure maximum. Also the extension of the parallel gap in $\mathrm{x}$-direction becomes slightly smaller and the constriction is more pronounced. For a hypothetical high value of $t_{\mathrm{c}}=400 \mu \mathrm{m}, p$ would rise to $130 \mathrm{~N} / \mathrm{mm}^{2}$ and the minimum film thickness would decrease slightly to $1.9 \mu \mathrm{m}$. Hence, the coating contributes only slightly to contact stiffness, but it results in different stresses in the substrate. Hence, most stresses occur in the coating and at the interface between coating and substrate. This is known from coated hard contacts, e.g. [45, 46]. Note that high stress gradients can cause reduction of adhesion and delamination of the coating.

The temperature $\vartheta$ within the coatings and adjoining lubricant is lower in the coated polymer than in the uncoated polymer (cf. Fig. 5). This is due to the higher thermal effusivity e of the coating compared to the polymer (cf. Table 1) resulting in a more pronounced heat removal. Hence, the lubricant temperature is lower and the coating can act as a thermal barrier protecting the polymer from detrimental heat. As a consequence, the effective viscosity and, therefore, shear stress, and friction are slightly higher than in the uncoated polymer-steel contacts.

\subsubsection{Variation of Coating Mechanical Properties}

Figure 11 (left) shows the hydrodynamic pressure $\mathrm{p}$ and the film thickness $h$ of coated polymer-steel contacts for coatings with Young's moduli of $E_{\mathrm{c}}=\{34 ; 110 ; 220 ; 420\} \mathrm{GPa}$ and a constant coating thickness of $t_{\mathrm{c}}=100 \mu \mathrm{m}$. Figure 11 (right) illustrates the effect of coating stiffness $E_{\mathrm{c}}=\{34$; $110\}$ GPa and coating thickness $t_{\mathrm{c}}$ on the stiffness expressed by the reduced Young's modulus $E^{\prime}$ of the TEHL contact. Thereby, the extension of the Hertzian theory presented by
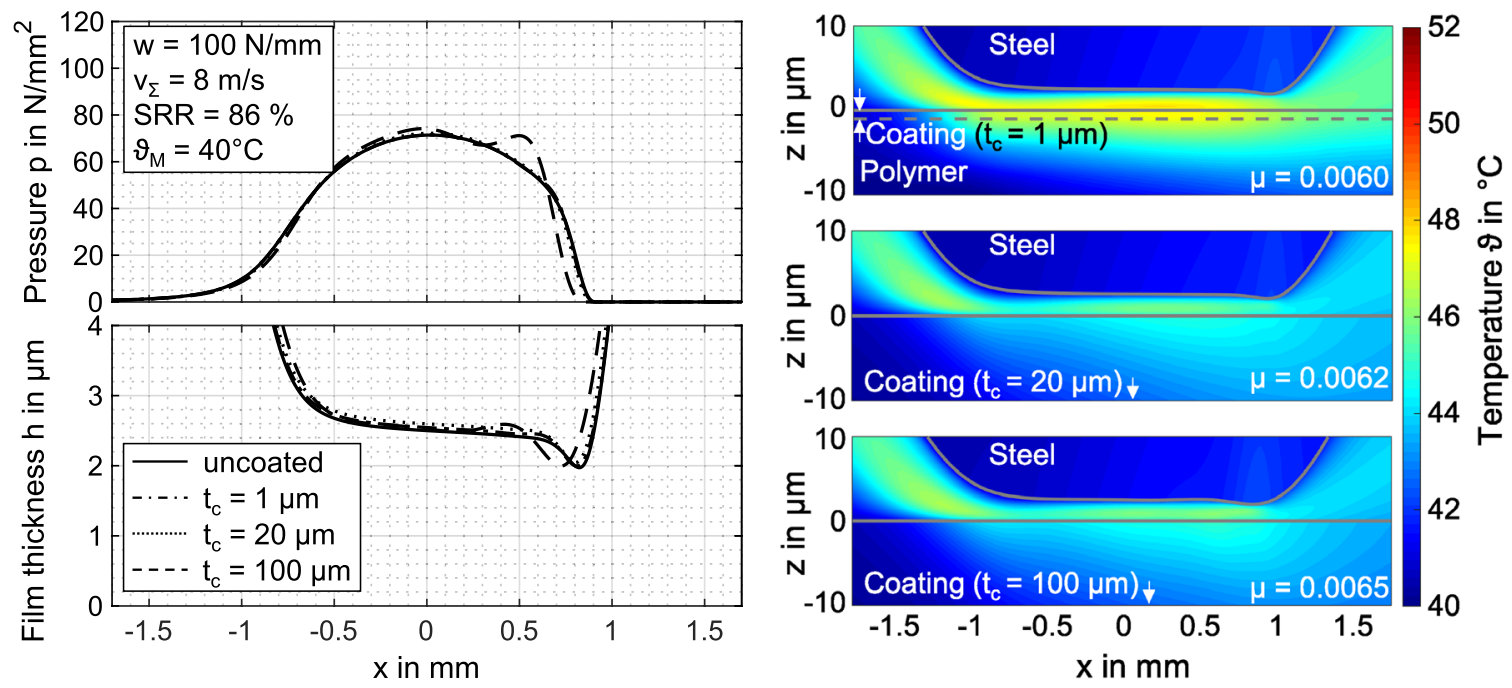

Fig. 10 Hydrodynamic pressure $p$, film thickness $h$ (left) and temperature $\vartheta$ (right) of an uncoated and coated polymer-steel contact with different coating thicknesses $t_{\mathrm{c}}$ 

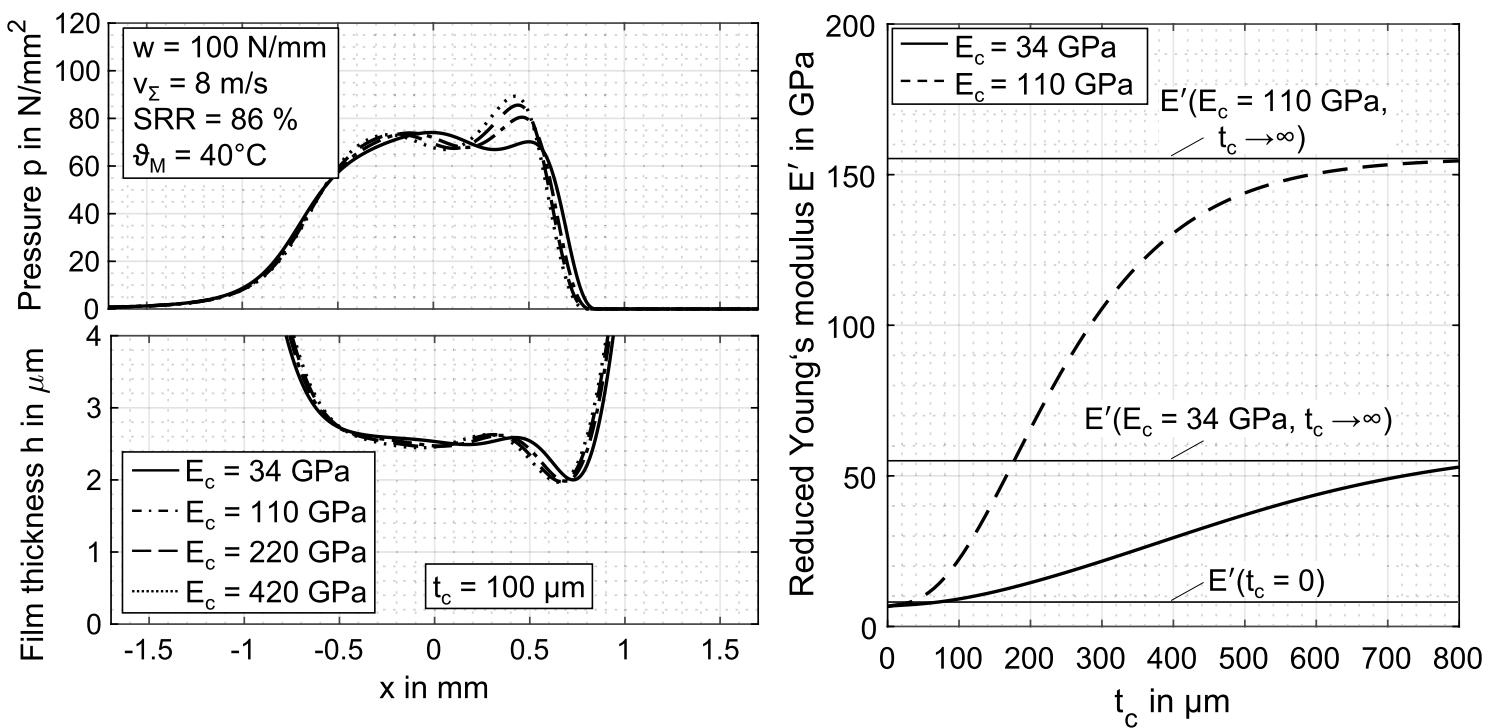

Fig. 11 Hydrodynamic pressure $p$ and film thickness $h$ for a constant coating thickness (left) and reduced Young's modulus $E^{\prime}$ for a coated polymer-steel contact with different coating's Young's modulus $E_{\mathrm{c}}$ (right)

Liu et al. [47] is used. All thermophysical properties are adopted from Table 1.

The hydrodynamic pressure $p$ shows a pronounced second pressure maximum and becomes more pronounced with increasing Young's modulus $E_{\mathrm{c}}$ of the coating. Additionally, the contact width slightly decreases and the constriction of the lubricant film thickness is more pronounced. This can be traced back to low contact stiffness of polymer-steel TEHL contacts. In general, the contact stiffness relevant for TEHL contacts depends on Young's modulus and Poisson's ratio of the regions which underlie strain and stress. In polymer-steel contacts, these regions are much larger. Hence, the coating's mechanical properties affect the relevant contact stiffness for polymer-steel contacts only at much higher coating thickness $t_{\mathrm{c}}$ or higher coating stiffness. Hence, the ratio of deformation between coated polymer and steel is not significantly affected by the coating and the deformed geometry of the rolling elements is similar to the uncoated polymer-steel contact (Fig. 2).

A higher thickness of hard coatings generally contributes to a higher stiffness of the contact. For hard TEHL contacts, it was shown that the influence of hard coatings on $p$ is negligible for small coating thickness $[18,20]$. With regard to the polymer-steel contact considered, which show low contact pressure and high deformation, the contribution of the coating's stiffness to the stiffness of the TEHL contact becomes relevant at approximately $t_{\mathrm{c}}>50 \mu \mathrm{m}$. This is retraced by the evaluation of the reduced Young's modulus $E^{\prime}$ in Fig. 11 (right). For an uncoated polymer-steel contact $E^{\prime}$ is $6.6 \mathrm{GPa}$. With increasing coating thickness $t_{\mathrm{c}}, E^{\prime}$ increases due to higher stiffness of the coating $E_{\mathrm{c}}$ compared to the polymer. At a thickness $t_{\mathrm{c}} \approx 800 \mu \mathrm{m}$, the coating with
$E_{\mathrm{c}}=110 \mathrm{GPa}$ reaches $E^{\prime} \approx 155 \mathrm{GPa}$, which represents a contact between pure coating material and steel. Hence, the influence of the substrate polymer on the contact stiffness vanishes. The coating with $E_{\mathrm{c}}=34 \mathrm{GPa}$ reaches this point at $t_{\mathrm{c}} \approx 1200 \mu \mathrm{m}$ with $E^{\prime} \approx 62 \mathrm{GPa}$. For a typical coating thickness of $t_{\mathrm{c}}<8 \mu \mathrm{m}$, no noticeable effect on the stiffness of polymer-steel contacts is expected.

\subsubsection{Variation of Coating Thermophysical Properties}

Figure 12 (left) shows the temperature $\vartheta$ in coated polymer-steel contacts for various coatings with thermal effusivities of $e_{\mathrm{c}}=\{578 ; 1156 ; 2312\} \mathrm{J} /\left(\mathrm{K} \sqrt{\mathrm{s}} \mathrm{m}^{2}\right)$ for a constant coating thickness of $t_{\mathrm{c}}=1 \mu \mathrm{m}$. The mechanical properties are adopted from Table 1. $e_{\mathrm{c}}=578 \mathrm{~J} /(\mathrm{K} \sqrt{\mathrm{s} \mathrm{m}})^{2}$ represents a coating with thermophysical properties similar to the polymer. Figure 12 (right) shows the effect of coating thickness $t_{\mathrm{c}}$ on the maximum temperatures in the lubricant, coating, polymer, and steel for the coating properties in Table 1.

With increasing thermal effusivity $e_{\mathrm{c}}$, the lubricant temperature $\vartheta$ decreases, and the coefficient of friction $\mu$ slightly increases (Fig. 12, left). This is in accordance with the results for uncoated contacts in Fig. 7. The coating shows a decrease in temperature penetration depth with increasing $e_{\mathrm{c}}$. This results in lower maximum temperatures at the coating-polymer interface. Hence, also very thin coatings $t_{\mathrm{c}}=1 \mu \mathrm{m}$ with higher thermal effusivity $e_{\mathrm{c}}$ than the polymer can act as thermal barrier protecting the polymer.

By increasing $t_{\mathrm{c}}$, the maximum temperature in the polymer decreases continuously (Fig. 12, right). For $t_{\mathrm{c}}=100 \mu \mathrm{m}$, no further temperature increase is observed. In this case, the heat penetration depth is less than the coating thickness. 

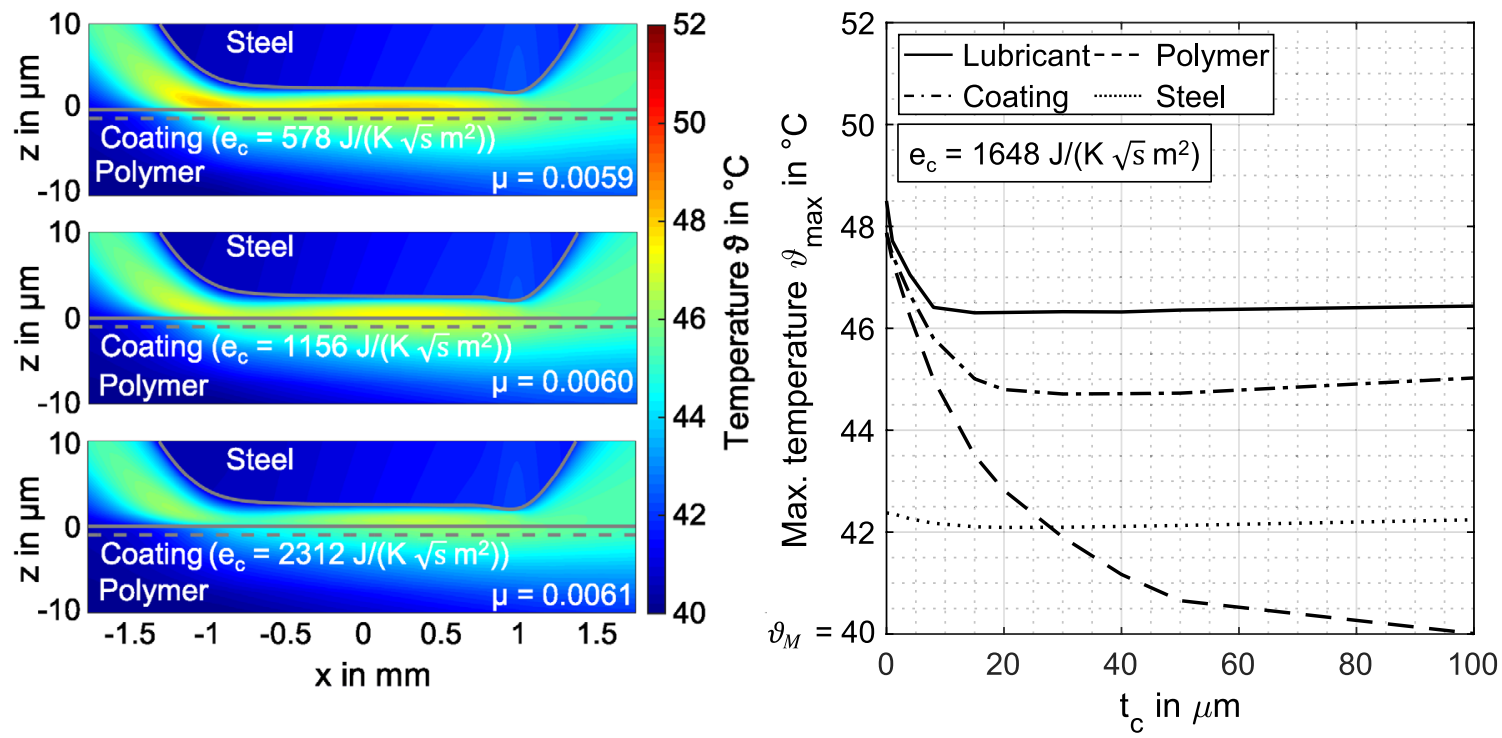

Fig. 12 Temperature $\vartheta$ in coated polymer-steel contacts with different coating thermal effusivities $e_{\mathrm{c}}$ (left) and maximum temperatures in lubricant, coating, polymer, and steel for different coating thicknesses $t_{\mathrm{c}}$ (right)

This results in maximum temperatures in the polymer equal to bulk temperature $\vartheta_{\mathrm{M}}$. In general, the maximum temperatures in the lubricant, coating and steel decrease with $t_{\mathrm{c}}$ up to approximately $t_{\mathrm{c}} \approx 30 \mu \mathrm{m}$. This decrease is most pronounced up to $t_{\mathrm{c}} \approx 8 \mu \mathrm{m}$. For approximately $t_{\mathrm{c}}>30 \mu \mathrm{m}$, these temperatures increase slightly. In general, the coatings considered contribute-by their higher thermal effusivity compared to the polymer-to an improved heat removal (Fig. 12). In contrast, due to increasing coating thickness $t_{\mathrm{c}}$, pressure (Fig. 10) and, therefore, shear stress and frictional heat increase slightly. Both influences has an inverse effect on temperature. Whereas the effect of the coating stiffness on the TEHL contact appears to be significant at approximately $t_{\mathrm{c}}>50 \mu \mathrm{m}$, the influence of the thermophysical properties of the coatings is already present at very low $t_{\mathrm{c}}<8 \mu \mathrm{m}$. A transition point is observed at approximately $t_{\mathrm{c}}=30 \mu \mathrm{m}$.

\subsubsection{Interim Summary}

Based on the presented results, the main findings on coated polymer-steel TEHL contacts are summarized:

- The mechanical properties of coatings only has a small influence on the TEHL contact stiffness and, therefore, on hydrodynamic pressure and film thickness, even for very high coating thickness.

- The local contact conformity known from uncoated polymer-steel contacts is also present for coated polymersteel contacts.
- The thermophysical properties of coatings have large influence on the temperature distribution in the TEHL contact, even at low coating thickness.

- Coated polymers in polymer-steel contacts can act as thermal barrier, thus protecting the polymer from contact heat, even at very low coating thickness.

\section{Conclusion}

In this study, uncoated and coated polymer-steel TEHL contacts were investigated by numerical simulation. The results show a local contact conformity between polymer and steel, with the polymer accounting for almost all of the deformation. The high temperatures are localized at the polymer surface due to inhibited heat removal. Polymers with higher Young's modulus show higher temperatures and hydrodynamic pressures as well as lower film thickness. Even for low Young's modulus and high deformation, elastic strain in the polymer is very small. For coated polymers, only small effects on film thickness and hydrodynamic pressure are observed, even for hypothetically high coating thicknesses. On the contrary, the contact temperature decreases even with thin coatings due to their higher thermal effusivity compared to the polymer. Hence, the coating can act as thermal barrier protecting the polymer from detrimental heat. In mixed lubrication, coated polymers can show potentials for protecting the polymer from abrasive wear. Beyond the scope of this study, viscoelasticity can have a significant influence on contact behavior and temperature of polymer-steel contacts. This will be focus of future work including experimental 
investigations on friction and temperature of coated polymer-steel contacts.

Acknowledgements Open Access funding provided by Projekt DEAL. The presented results are based on the research project STA 1198-151, supported by the German Research Foundation e.V. (DFG). The authors would like to thank for the sponsorship and support received from the DFG.

Open Access This article is licensed under a Creative Commons Attribution 4.0 International License, which permits use, sharing, adaptation, distribution and reproduction in any medium or format, as long as you give appropriate credit to the original author(s) and the source, provide a link to the Creative Commons licence, and indicate if changes were made. The images or other third party material in this article are included in the article's Creative Commons licence, unless indicated otherwise in a credit line to the material. If material is not included in the article's Creative Commons licence and your intended use is not permitted by statutory regulation or exceeds the permitted use, you will need to obtain permission directly from the copyright holder. To view a copy of this licence, visit http://creativecommons.org/licenses/by/4.0/.

\section{References}

1. Bobzin, K., Brögelmann, T., Kalscheuer, C., Thiex, M., Stahl, K, Lohner, T., Maier, E., Reitschuster, S.: Steigerung der Leistungsfähigkeit technischer Kunststoffe durch DLC-Beschichtungen [Improved Tribological Performance of Technical Plastics by DLC]. In: Proceeding of the 60th German Tribology Conference (GfT) Göttingen (2019)

2. Esfahanian, M., Hamrock, B.J.: Fluid-film lubrication regimes revisited. Tribol. Trans. (1991). https://doi.org/10.1080/10402 009108982081

3. Marx, N., Guegan, J., Spikes, H.A.: Elastohydrodynamic film thickness of soft EHL contacts using optical interferometry. Tribol. Int. (2016). https://doi.org/10.1016/j.triboint.2016.03.020

4. Leeuwen van, H.J., Schouten, M.J.W.: Die Elastohydrodynamik: Geschichte und Neuentwicklungen [Elastohydrodynamic: History and new Development]. VDI-Report No. 1207, VDI-Verlag, Düsseldorf, Germany (1995)

5. Stupkiewicz, S., Lengiewicz, J., Sadowski, P., Kucharski, S.: Finite deformation effects in soft elastohydrodynamic lubrication problems. Tribol. Int. (2016). https://doi.org/10.1016/j.tribo int.2015.03.016

6. De Vicente, J., Stokes, J.R., Spikes, H.A.: The frictional properties of Newtonian fluids in rolling-sliding soft-EHL contact. Tribol. Lett. (2005). https://doi.org/10.1007/s11249-005-9067-3

7. Bohan, M., Fox, I.J., Claypole, T.C., Gethin, D.T.: Numerical modelling of elastohydrodynamic lubrication in soft contacts using non-Newtonian fluids. Int. J. Numer. Methods Heat Fluid Flow (2002). https://doi.org/10.1108/09615530210433297

8. Johnson, K.L.: Regimes of elastohydrodynamic lubrication. J. Mech. Eng. Sci. (1970). https://doi.org/10.1243/ JMES_JOUR_1970_012_004_02

9. Myers, T.G., Hall, R.W., Savage, M.D., Gaskell, P.H.: The transition region of elastohydrodynamic lubrication. Proc. R. Soc. A Math. Phys. Eng. Sci. (1991). https://doi.org/10.1098/ rspa.1991.0026

10. Kummer, H.W.: Unified Theory of Rubber and Tire Friction. Technical Report, Pennsylvania State University, Bulleting (1966)
11. Hooke, C.J., Huang, P.: Elastohydrodynamic lubrication of soft viscoelastic materials in line contact. Proc. Inst. Mech. Eng. (1997). https://doi.org/10.1243/1350650971542417

12. Cerne, B., Duhovnik, J., Tavcar, J.: Semi-analytical flash temperature model for thermoplastic polymer spur gears with consideration of linear thermo-mechanical material characteristics. J. Comput. Des. Eng. (2019). https://doi.org/10.1016/j.jcde.2019.03.001

13. Hasl, C., Illenberger, C., Oster, P., Tobie, T., Stahl, K.: Potential of oil-lubricated cylindrical plastic gears. J. Adv. Mech. Des. Syst. Manuf. (2018). https://doi.org/10.1299/jamdsm.2018jamdsm0016

14. Fürstenberger, M.: Betriebsverhalten verlustoptimierter Kunststoffzahnräder: Verzahnungsverluste, Temperaturen, Tragfähigkeit und dynamisches Betriebsverhalten [Operating behavior of lossoptimized plastic gears: gear power loss, temperature, load carrying capacity and dynamic operating behavior], $\mathrm{Ph} . \mathrm{D}$. Thesis, Technical University of Munich, Munich (2013)

15. Illenberger, C., Tobie, T., Stahl, K.: Flank load carrying capacity of oil-lubricated high perfor-mance plastic gears - Analysis of the pitting development in back-to-back tests. Forsch. Ingenieurwes. (2019). https://doi.org/10.1007/s10010-019-00332-x

16. Grill, A.: Review of the tribology of diamond-like carbon. Wear (1993). https://doi.org/10.1016/0043-1648(93)90210-D

17. Björling, M., Larsson, R., Marklund, P.: The effect of DLC-coating thickness on elastohydrodynamic friction. Tribol. Lett. (2014). https://doi.org/10.1007/s11249-014-0364-6

18. Björling, M., Habchi, W., Bair, S., Larsson, R., Marklund, P.: Friction reduction in elastohydrodynamic contacts by thin-layer thermal insulation. Tribol. Lett. (2014). https://doi.org/10.1007/ s11249-013-0286-8

19. Ziegltrum, A., Lohner, T., Stahl, K.: TEHL simulation on the influence of lubricants on the frictional losses of DLC coated gears. Lubricants (2018). https://doi.org/10.3390/lubricants60100 17

20. Habchi, W.: A Numerical model of the solution of thermal elastohydrodynamic lubrication in coated circular contacts. Tribol. Int. (2014). https://doi.org/10.1016/j.triboint.2014.01.002

21. Bobzin, K., Brögelmann, T., Kalschuer, C., Thiex, M., Ebner, M., Lohner, T., Stahl, K.: A contribution to the thermal effects of DLC-coatings in fluid friction in EHL contacts. Lubr. Sci. (2017). https://doi.org/10.1002/ls.1421

22. Elsharkawy, A.A., Holmes, M.J.A., Evans, H.P., Snidle, R.W. Micro-elastohydrodynamic lubrication of coated cylinders using coupled differential deflection method. Proc. Inst. Mech. Eng. (2006). https://doi.org/10.1243/13506501J10005

23. Habchi, W., Bair, S.: Effect of lubricant rheology on friction in coated elastohydrodynamic lubricated contacts. Proc. Inst. Mech. Eng. (2017). https://doi.org/10.1177/1350650116684657

24. Martinez-Martinez, D., De Hosson, J.T.M.: On the deposition and properties of DLC protective coatings on elastomers: a critical review. Surf. Coat. Technol. (2014). https://doi.org/10.1016/j. surfcoat.2014.08.016

25. Maier, E., Ziegltrum, A., Lohner, T., Stahl, K.: Characterization of TEHL contacts of thermoplastic gears. Forsch. Ingenieurwes. (2017). https://doi.org/10.1007/s10010-017-0230-4

26. Deutsche Edelstahlwerke $\mathrm{GmbH}$ : Materialdatenblatt für [Material data sheet of] 1.7131/1.7139 (16MnCr5/16MnCrS5). Witten, https ://www.dew-stahl.com/fileadmin/files/dew-stahl.com/documents/ Publikationen/Werkstoffdatenblaetter/Baustahl/1.7131_1.7139_ de.pdf. (2011) Accessed 19 Nov 2019

27. Reddyhoff, T., Schmidt, A., Spikes, H.: Thermal conductivity and flash temperature. Tribol. Lett. (2019). https://doi.org/10.1007/ s11249-018-1133-8

28. Habchi, W., Bair, S.: The role of the thermal conductivity of steel in quantitative elastohydrodynamic friction. Tribol. Int. (2020). https://doi.org/10.1016/j.triboint.2019.105970 
29. Liu, H.C., Zhang, B., Bader, N., Poll, G., Venner, C.H.: Influences of solid and lubricant thermal conductivity on traction in an EHL circular contact. Tribol. Int. (2020). https://doi.org/10.1016/j.tribo int.2019.106059

30. Becker, J., Colas, M., Gies, A., Hessel, S., Karner, H., Seibert, F., Stelzit, T.: Thermal effects influencing stability and performance of coatings in automotive applications. Surf. Coat. Technol. (2015). https://doi.org/10.1016/j.surfcoat.2015.06.085

31. Bair, S.: The temperature and pressure dependence of viscosity and volume for two reference liquids. Lubr. Sci. (2016). https:// doi.org/10.1002/1s.1302

32. Murnaghan, F.D.: The compressibility of media under extreme pressures. Proc. Natl. Acad. Sci USA (1944). https://doi. org/10.1073/pnas.30.9.244

33. Doolittle, A.K.: Studies in Newtonian flow. II. The dependence of the viscosity of liquids on free-space. J. Appl. Phys. (1951). https ://doi.org/10.1063/1.1699894

34. Bair, S.: A rough shear thinning correction for EHD film thickness. Tribol. Trans. 47(3), 361 (2004)

35. Carreau, P.J.: Rheological equations from molecular network theories. Trans. Soc. Rheol. (1972). https://doi.org/10.1080/05698 190490455519

36. Lohner, T., Ziegltrum, A., Stemplinger, J.-P., Stahl, K.: Engineering software solution for thermal elastohydrodynamic lubrication using multiphysics software. Adv. Tribol. (2016). https://doi. org/10.1155/2016/6507203

37. Valerio, M., Ziegltrum, A., Maier, E., Lohner, T., Stahl, K.: EHL simulation apps advance tribology research. COMSOL News 2018, 24-27 (2018)

38. Ziegltrum, A., Lohner, T., Stahl, K.: TEHL Simulation on the influence of lubricants on load-dependent gear losses. Tribol. Int. (2016). https://doi.org/10.1016/j.triboint.2016.12.018

39. Yang, P., Wen, S.: A generalized Reynolds equation for non-Newtonian thermal elastohydrodynamic lubrication. ASME J. Tribol. (1990). https://doi.org/10.1115/1.2920308
40. Habchi, W., Eyheramendy, D., Vergne, P., Morales-Espejel, G.: A full-system approach of the elastohydrodynamic line/point contact problem. J. Tribol. (2008). https://doi.org/10.1115/1.2842246

41. Habchi, W.: Coupling strategies for finite modeling of thermal elastohydrodynamic lubrication problems. J. Tribol. (2016). https ://doi.org/10.1115/1.4034956

42. Maier, E., Sperka, P., Lohner, T., Stahl, K., Hartl, M.: Detailed analyses of film thickness and friction in thermoplastic EHL contacts. In: Proceedings of the International Conference on Gears, Garching (2019)

43. CampusPlasitcs: Satinice df23 zk6BR - PMMA, https://www. campusplastics.com/material/pdf/101488/PLEXIGLASSatini cedf23zk6BR?sLg=de. (2019). Accessed 10 Jan 2020

44. Dowson, D., Higginson, G.: New roller bearing lubrication formula. Engineering 192, 158 (1961)

45. Yilmaz, M., Kratzer, D., Lohner, T., Michaelis, K., Stahl, K.: A study on highly-loaded contacts under dry lubrication for gear applications. Tribol. Int. (2018). https://doi.org/10.1016/j.tribo int.2018.07.016

46. King, R.B., O'Sullivan, T.C.: Sliding contact stresses in a twodimensional layered elastic half-space. Int. J. Solids Struct. (1987). https://doi.org/10.1016/0020-7683(87)90019-9

47. Liu, S., Peyronnel, A., Wang, Q.J., Keer, L.M.: An extension of the hertz theory for 2D coated components. Tribol. Lett. (2010). https://doi.org/10.1007/s11249-005-3611-z

Publisher's Note Springer Nature remains neutral with regard to jurisdictional claims in published maps and institutional affiliations. 